Available online on 15.05.2018 at http://jddtonline.info
Journal of Drug Delivery and Therapeutics
Open Access to Pharmaceutical and Medical Research
$\begin{gathered}\text { O 2011-18, publisher and licensee JDDT, This is an Open Access article which permits unrestricted non- } \\ \text { commercial use, provided the original work is properly cited }\end{gathered}$

Open $\odot$ Access

Review Article

\title{
HERBAL NOVEL DRUG DELIVERY SYSTEMS AND TRANSFERSOMES
}

\author{
Chauhan Pradeep *, Tyagi Bharat Kumar \\ Institute of Professional Studies-College of Pharmacy, Shivpuri Link Road, Gwalior (M.P.) 474007- India
}

\section{ABSTRACT}

The strength of any herbal formulation depends on the delivery of phytoactives to an effective level. This limitation can be overcome by development of novel drug delivery systems, which ensure optimized drug delivery, enhanced bioavailability and better stability of phyto constituents for better therapeutic effects. Several novel herbal delivery systems have been successfully developed in recent years like liposomes, phytosomes, solid-lipid nanoparticles, ethosomes, microemulsions and various other vesicular systems. Transfersomes are vesicular drug delivery system having almost same structure like liposomes, but with better skin penetration properties to deliver the drugs at deeper skin tissues. Transfersomes are better drug delivery agents due to their ultradeformable structure.

Keywords: Herbal, Novel Drug Delivery, Transfersomes

Article Info: Received 24 March, 2018; Review Completed 04 May 2018; Accepted 06 May 2018; Available online 15 May 2018

Cite this article as:

Chauhan P, Tyagi BK, Herbal novel drug delivery systems and transfersomes, Journal of Drug Delivery and Therapeutics. 2018; 8(3):162-168 DOI: http://dx.doi.org/10.22270/jddt.v8i3.1772

*Address for Correspondence:

Pradeep Chauhan, Institute of Professional Studies-College of Pharmacy, Shivpuri Link Road, Gwalior (M.P.) 474007- India

\section{INTRODUCTION}

From time immemorial it has been the endeavor of the physician and the apothecary to provide patients with the best possible forms of medicines so that recovery from disease is faster and complete. The drugs are delivered in a suitable formulation keeping in view the safety, efficacy and acceptability among other factors, and the formulation is usually known as dosage form or drug delivery system. With the progress in all spheres of science and technology, the dosage forms have evolved from simple mixtures and pills to highly sophisticated technology intensive drug delivery systems, which are known as Novel Drug Delivery Systems (NDDS) ${ }^{1}$.

Much research is being carried out on single herbs, polyherbal formulations or herbo-mineral compounds, pharmaceutical products, combined treatments and disease specific therapies. However, the path remains uncertain in terms of standardization of products along with safety and efficacy for universal acceptance ${ }^{2}$.

Herbal drugs are becoming more popular in the modern world for their application to cure variety of diseases with less toxic effects ${ }^{3}$.
The majority of biological active constituents in plants are water soluble like flavonoids, glycosides, tannins etc. These phytoconstituents are weakly absorbed, either owing to their giant molecular mass that can not be absorbed by inert transmission or owing to their reduced macromolecular solubility, a factor that severely restricts their capability to pass through the lipid rich natural membrane, following reduced bioavailability. In novel drug delivery technology, control of the distribution of drug is achieved by incorporating the drug in carrier system or by changing the drug behavior at the molecular level.

Some limitation of herbal extracts / plant actives are, instability at high $\mathrm{pH}$, liver metabolism which has lead to drug level below therapeutic concentration in the blood, resulting in less or no therapeutic effects.

Other problems which are associated with herbal formulation are dose adjustment, maintenance of drug release pattern, which reduced efficacy of such system. 


\section{Advantage of Herbal Novel Drug Delivery System}

Delivery of phytoactives through novel drug delivery systems has various advantages over conventional dosage forms.

- Incorporation of novel drug delivery technology to herbal of phytoactives minimizes the drug degradation or pre-systemic metabolism and other side effects by accumulation of drugs to the nontargeted areas and improves the ease of administration

- Novel drug delivery system is advantageous in delivering the herbal drug at predetermined rate and delivery of drug at the site of action, which minimizes the toxic effects with increased bioavailability of drugs.

- Incorporation of herbal drugs in the delivery system also aids to increase in solubility, enhanced stability, protection from toxicity, enhanced pharmacological activity, improved tissue macrophage distribution, sustained delivery and protection from physical and chemical degradation.

- Throughout the extraction method, the drug molecules within the herbal medication are exposed to oxidation, reduction or many other chemical reactive functional groups which cause degradation in phytoactive molecules. A nanocoating of those drug molecules protects the active chemicals from degradations and thus enhance the stability and efficacy.

- It may help in increasing the efficacy and reducing the side effects of various herbal compounds and herbs.

- Some drugs have an optimum concentration range within which maximum benefit is derived, and concentrations above or below this range can be toxic or produce no therapeutic benefit, herbal novel drug delivery systems eliminates this limitation by delivering the correct amount of drug at predetermined controlled manner.

\section{Types of herbal Novel Drug Delivery Systems}

There are various novel drug delivery systems for herbal molecules are based on:

\section{(a) Vascular delivery systems: \\ Transfersomes, Ethosomes, Liposomes, Phytosomes}

\section{(b) Nano drug delivery systems:}

Micropallets, Microspheres, Nanoparticles

(c) Biphasic drug delivery systems:

Micro and Nano-emulsions

Table 1: Various Novel Drug Delivery Systems for Phytoactives.

\begin{tabular}{|c|c|c|}
\hline Delivery System & Description & Ref \\
\hline Invasome & $\begin{array}{l}\text { Invasomes are the liposomal vesicles, which act as potential carriers with increased skin } \\
\text { penetration. Invasomes have higher penetration rate through the skin as compared to } \\
\text { liposomes and ethosomes. }\end{array}$ & 4 \\
\hline Ethosomes & $\begin{array}{l}\text { Ethosomes are noninvasive delivery carriers that enable drugs to reach the deep skin } \\
\text { layers and/or the systemic circulation. These are soft, malleable vesicles tailored for } \\
\text { enhanced delivery of active agents. }\end{array}$ & 5 \\
\hline Pharmacosomes & $\begin{array}{l}\text { Pharmacosomes are colloidal dispersions of drugs covalently bound to lipids, and may } \\
\text { exist as ultrafine vesicular, micellar, or hexagonal aggregates, depending on the chemical } \\
\text { structure of drug-lipid complex. }\end{array}$ & 6 \\
\hline Vesosomes & $\begin{array}{l}\text { A Vesosome is a more or less heterogeneous, aggregated, a large lipid bi-layer enclosing } \\
\text { multiple, smaller liposomes that offers a second barrier of protection for interior } \\
\text { components and can also serve as the anchor for active targeting components. }\end{array}$ & 7 \\
\hline Sphingosomes & $\begin{array}{l}\text { Sphingosomes is bilayer vesicles in which an aqueous volume is entirely enclosed by } \\
\text { membrane lipid bilayer mainly composed of natural or synthetic sphingolipid. } \\
\text { Sphingosomes showed higher stability, less in-vivo circulation time. Used to deliver } \\
\text { chemotherapeutic agent and biological macromolecule. }\end{array}$ & 8 \\
\hline Niosomes & $\begin{array}{l}\text { Niosomes are non-ionic surfactant based vesicles that have a similar structure to that of } \\
\text { phospholipid vesicles like liposomes. They have ability to increase the stability of } \\
\text { entrapped drugs, improved bioavailability of poorly absorbed ingredients and enhanced } \\
\text { skin penetration. }\end{array}$ & 9 \\
\hline Nanoparticles & $\begin{array}{l}\text { Solid lipid nanoparticles are composed of lipid matrix, which becomes solid at room } \\
\text { temperature and also at the body temperature. The main features of solid lipid } \\
\text { nanoparticles (SLNs) with regard to parenteral application are the excellent physical } \\
\text { stability, protection of incorporated labile drugs from degradation. }\end{array}$ & 10 \\
\hline Nano-emulsions & $\begin{array}{l}\text { Micro-emulsion is also called nano-emulsion, and the sub-micro-emulsion is also called } \\
\text { lipid emulsion. Emulsion drug delivery system is targeted or distributed well due to } \\
\text { affinity to lymph Micro-emulsions are solutions containing nanometre-sized droplets of } \\
\text { an immiscible liquid dispersed in an aqueous buffer. }\end{array}$ & 11 \\
\hline
\end{tabular}


Table 2: Various Vesicular Systems used for herbal drug delivery

\begin{tabular}{|c|c|c|}
\hline Vesicular System & Advantages & Limitation \\
\hline Liposomes & Biocompatible, Biodegradable & Stability issue, less penetration property \\
\hline Niosomes & Improved stability due to use of non-ionic surfactants & Skin penetration is not much effective \\
\hline Transfersomes & $\begin{array}{l}\text { Ultradeformable with high stability, high penetration } \\
\text { property, biodegradable, bio-compatible, incorporate } \\
\text { low and high molecular weight drugs, penetrate } \\
\text { deeper skin regions. }\end{array}$ & Difficulty in loading hydrophobic drugs \\
\hline Phytosomes & $\begin{array}{l}\text { Higher Bioavailability, enhanced capacity to cross the } \\
\text { lipid rich biomembranes, better pharmacokinetic and } \\
\text { therapeutic profile }\end{array}$ & leaching of the phytoconstituents \\
\hline Ethosomes & $\begin{array}{l}\text { Increased stability, increased skin permeability and } \\
\text { inexpensive to formulate }\end{array}$ & $\begin{array}{l}\text { Loss of product during transfer form } \\
\text { organic to water media }\end{array}$ \\
\hline
\end{tabular}

\section{TRANSFERSOMES}

The name means 'carrying bodies'. Transfersomes word is derived from the latin word 'transferee' which means 'to carry across' and the greek word "soma' which is used for a body. Transfersomes are a type of liposomes 12 .

The basic structure of transfersomes is like classic liposomes, still it has some differences from liposomes by soft nature, ultra-deformable properties, and better adjustable nature of system membrane.

An important property of transfersomes is its ability to bind with skin moisture and retain water. Transfersomes contains high amount of hydrophilic molecules to avoid dehydration.

The first generation of Transfersomes includes vesicles, composed of phospholipids with edge activators. The second generation of transfersomes is composed by a combination of a bilayer component (e.g. phosphatidylcholine) and more than one amphipathic membrane destabilizing component. The third generation of transfersomes is constituted by amphipathic non-phospholipidic bilayers, but unlike the first and second generation, the surfactant is replaced by water soluble modulator compounds (e.g. organic ions) that have the same efficasy ${ }^{13}$.

When the transfersomes applied to the skin they move deeper towards the water containing strata to acquire their hydration. Skin barrier penetration of transfersomes is due to reversible bilayer ultradeformation, but without losing its integrity ${ }^{14}$.
It was claimed that the presence of water gradient exert a force in the order of 10 " $\mathrm{N}$ per vesicle of a radius of approximately $60 \mathrm{~nm}$. As a result of this force the deformable vesicles can be squeezed through lipid bilayer. A low interracial tension makes them more deformable ${ }^{15}$.

Transport driving force magnitude plays an important role on the penetration, as

Flow $=$ area $\mathrm{X}$ force $\mathrm{X}$ permeability

The mechanism of transfersomes penetration can be explain in steps as initial interaction between hydrophilic lipid residue and proximal water, from there the polar lipid attracts water molecules, which leads induced hydration, the vesicle moves toward the site of more water concentration. A trans-epidermal osmotic gradient develops, leads to penetration of transfersomes across skin ${ }^{16}$.

Another possible explanation for the fact that transfersomes are able to deliver molecules under nonoccluded conditions could be that, as a result of water evaporation from the applied sodium-cholate phospholipid aggregate system, concentrated micellar system of cholate or collate-phospholipid or both generated. The micelles may further delipidize the stratum corneum creating small pores through which drug penetrates.

\section{Methods of Transfersomes Preparation}

Various chemicals are used in formulation of transfersomes, having various roles i.e. phospholipids, surfactants, dyes, alcohol, buffering agents etc.

Table 3: Various ingredients and their role for synthesis of Transfersomes

\begin{tabular}{|l|l|l|}
\hline Ingredients & Chemical & Role \\
\hline Phospholipids & $\begin{array}{l}\text { Phosphatidyl choline, soya Phosphatidyl choline, dipalmitoyl } \\
\text { phosphatidyl choline }\end{array}$ & Formation of vesicles \\
\hline $\begin{array}{l}\text { Surface active agents } \\
\text { (edge activators) }\end{array}$ & Sodium Cholate, Sodium deoxycholate, tween 80, span 80 & Flexibility improvement \\
\hline Primary alchohol & Ethanol, Methanol & Solvents \\
\hline Buffering agents & $\mathrm{pH}$ 6.4, phosphate Saline & Hydration medium \\
\hline
\end{tabular}




\section{Thin film hydration method}

In this method, phospholipids and surfactants are dissolved in suitable organic medium, such as chloroform-methanol and prepared a thin film, using rotary evaporator. The organic solvent evaporated at above the lipid transition temperature at $50^{\circ} \mathrm{C}$.

Saline phosphate buffer of $\mathrm{pH} 6.4$ is added to hydrate stack of film and subsequently kept for rotation at 60rpm for $1 \mathrm{hr}$. kept at room temperature for $2 \mathrm{hrs,} \mathrm{till}$ the swelling of vesicle is completed. Afterwards to achieve desired size, the dispersion is sonicated ${ }^{17}$.

\section{Modified Hand Shaking Lipid Film Hydeation Method}

Phytoconstituent, phosphatidyl choline (lecithin) and other additives, such as edge activators (sodium cholate) are dissolved in chloroform-ethanol mixture $(1: 1)$. The mixture of organic solvent is removed by evaporation by using rotary evaporator or by hand shaking at approximate $43^{\circ} \mathrm{C}$.

A stack of thin film of lipid is formed over the inner wall of flask. The obtained stack on inner wall is kept overnight under vacuumed for complete removal of traces of solvents. The phosphate buffer $(\mathrm{pH} 4)$ is added to rehydrate the film with hand shaking foe $15 \mathrm{~min}$. at mentioned temperature. The vesicle of desired size can be obtained by sonication ${ }^{17}$.

\section{Optimization factors of transfersomes formulation}

The numbers of process variables are responsible to obtain the optimized formulation of transfersomes. There are various factors that are responsible for the same are:

\section{1. $\mathbf{p H}$}

The $\mathrm{pH}$ evaluated by potentiometry affects the molecule ionization and consequently its interaction and entrapment efficiency. The $\mathrm{pH}$ level should be suitable for achieving a balance between formulation properties and biological applications, including the administration route ${ }^{18,19}$.

\section{Effect of phosphatidyle choline, edge activator ratio-}

These should be an optimized ratio of phosphatidylecholine and edge activator, because this affects greatly the entrapment efficiency. Higher concentration of edge activators may decrease entrapment efficiency. Upon incorporation of edge activators in low concentration, growth in vesicle size occurred ${ }^{20}$, whereas further increase in the content of edge activator may have led to pore formation in the bilayer and reduced penetration.

\section{Effect of type of edge activator-}

Deformability and entrapment efficiency of transfersomes is affected by the type of edge activators, which could be interpreted by difference in their chemical structure. One way to explain this effect is to consider the HLB of edge activators. In one finding, tween $80-3$ showed higher deformability. This could be attributed to the highly flexible and non-bulky hydrocarbon chain of tween-80. Sodium deoxycholate (SDC-3) and Sodium cholate (SC-3) has lower deformability than tween-80-3 due to thin steroid like structure, which are bulkier than hydrocarbon chains of tween 80. This could be a result of their high hydrophobicity, which reduced the formation of transient hydrophilic holes, hence, minimizing the amphiphillic property of the bilayer responsible for membrane fluidity ${ }^{21}$.

\section{Effect of Total lipid concentration-}

Various research findings indicated that the fraction of lipid taking part in encapsulation was reduced upon increasing the total lipid concentration. Total lipid concentration used for formulation affects entrapment efficiency $^{22}$.

Edge activators influenced the vesicular morphology, entrapment efficiency, zeta potential, drug release, deformability, skin permeation, and skin deposition.

\section{Evaluation Parameters}

Different parameters are used for characterization and optimization of transfersomes:

(A) Entrapment efficiency- the entrapment efficiency is the amount of drug entrapped in the formulation. This is determined by separating the entrapped drug in vesicles by using various techniques i.e. minicolumn centrifugation. After that the vesicles were disrupted using $0.1 \%$ triton $\mathrm{X}-100$ or $50 \% \mathrm{n}$ propanol.

The entrapment efficiency is calculated by using this formula

Entrapment efficiency $=\frac{\text { amount of drug entrapped }}{\text { total amount of drug added }} X 100$

(B) Diameter of Vesicle- Photon correlation spectroscopy or dynamic light scattering method is used to determine vesicle diameter. Distilled water is used for the preparation of sample and filtered through a membrane filter $(0.2 \mathrm{~mm})$ and filtered saline used to dilute up to certain dilution ratio to measure the size of vesicles.

(C) Degree of deformability or permeability measurement- this is an important parameter for characterization as this greatly affects the permeation of formulation. This study is done by passing the preparation through a large number of pores of known size (micro porous filters of 50-400 nm) 23 .

Particle size and size distribution are noted after each pass by dynamic light scattering (DLS) measurements.

$$
\mathrm{D}=\mathrm{J}(\mathrm{rv} / \mathrm{rp})
$$

Where

$\mathrm{D}=$ degree of deformability

$\mathrm{J}=$ amount of suspension extruded during $5 \mathrm{~min}$.

$\mathrm{rv}=$ size of vesicle

$\mathrm{rp}=$ pore size of barrier 
(D) Measurement of turbidity: Nephelometer is used to measure turbidity sample in aqueous solution.

(E) Surface charge and charge density: Zeta sizer is used to measure the surface charge and charge density on transfersomes.

(F) Number of vesicles per cubic mm- Unsonicated transfersomes formulation, diluted 5 times with $0.9 \%$ sodium chloride solution. Hemocytometer with optical microscope are used for this study.

The transfersomes in 80 small squares are counted and calculated using formula;

(Total number of transfersomes) $\mathrm{mm}^{3}=$

Total number of vesicle counted X dilution factor X 4000 Total number of square counted

(G) Vesicle Morphology- vesicle diameter can be determined using photon correlation spectroscopy (PCS) or Dynamic Light Scattering (DLS). Samples were prepared in distilled water, filtered through a $0.2 \mathrm{~mm}$ membrane filter and dilutes with filtered saline and then size measurement can be done by using PCS or DLS.

Transfersomes vesicles can be visualized by Transmission electron microscopy (TEM) or pby phase contrast microscope. Mean size is measured by DLS and TEM, structural changes are observed by TEM ${ }^{24}$.

\section{APPLICATION OF TRANSFERSOMES}

Transfersomes have a wide variety of applications in the targeting of drug and other molecules through the transdermal route.

\section{Delivery of Proteins-}

It is very difficult to transport big and large biogenic molecules such as body proteins and peptides into body. When administered through oral route, such molecule shows degradation in gastrointestinal tract ${ }^{25}$.

Transfersomes are the best suitable approach for the delivery of all kinds of proteins into body. It is observed that bioavailability of the molecules delivered by transfersomes are similar to the drug administered by subcutaneous injections ${ }^{26,27}$.

The protein preparation e.g. bovine serum albumin (immunogenic adjuvent) applied repeatedly in the preparation of transfersomes through epi-cutaneous route, showed strong immunogenic response.
Transfersomes has been shown to penetrate the skin intact, to present the antigen to dendritic cells and elicit an antigen specific immune response ${ }^{28}$.

Gap junction proteins loaded in transfersomes elicit antigen specific antibody titer that was equivalent to subcutaneous route ${ }^{29}$.

Plasmid DNA encoding Hepatitis-B surface antigen (HBs-Ag)- loaded cationic transfersomes are also utilized for topical immunization, and showed significantly higher HBs-Ag antibody titer and cytokinins level ${ }^{30}$.

\section{Delivery of Anti-cancer drugs}

Transfersomes are used as carrier for delivery of anticancer drugs; they are suitable specially for treating skin cancers. Transfersomes loaded with methotraxate was tried for treatment of skin cancer. Tamoxifen (TAM) anti breast cancer agent is carried through skin most efficiently by means of transfersomes and accelerate the growth of murine uteri, where it act as an anti-oestrogen, even at low dose as $0.1-0.2 \mathrm{mg} / \mathrm{kg} / \mathrm{day}{ }^{31}$.

\section{Delivery of Interferon-}

Transfersomes loaded with immunomodulators, Interferon- $\alpha$ and interleukines-2 (IL-2) are successfully synthesized and observed that both the molecules retained their biological activity and could be efficiently encapsulated in carrier ${ }^{32}$.

\section{Insulin Delivery-}

Orally applied polypeptidic or proteinaceous drugs are digested in the gastro-intestinal tract, by and large, and thus are therapeutically nearly inactive. Transfersomes can transport their associated drugs, including the epicutaneously applied insulin, into the body spontaneously. This happens in spite of the fact that insulin is normally prevented from crossing the skin by its high molecular weight of 5808 Da. The selfregulating membrane deformability of transfersomes is closely related to the corresponding vesicles selfreparation capability, the latter being essential for the transfersome stability and practical usefulness. Insulin is inferred to be transported into the body between the intact skin cells with a bio-efficiency of at least $50 \%$ of the subcutaneous dose action ${ }^{33}$.

\section{Delivery of various therapeutic agents}

Table 2: Various Drugs used with Transfersomal drug delivery system

\begin{tabular}{|l|l|l|l|}
\hline Drug & Category & Therapeutic activity & Ref \\
\hline Dexamethasone & Corticosteroid Drug & Anti-edema activity & 34 \\
\hline Diclofenac & NSAID agent & Formulation optimization & 35 \\
\hline Tacrolimus & Immunosuppressive & Atopic dermatitis & 36 \\
\hline Pentoxifyllin & Xanthine Derivative & Chronic occlusive arterial disease. & 37 \\
\hline Eprosartan Mesylate & $\begin{array}{l}\text { Angiotensin receptor blockers } \\
\text { (ARBs) }\end{array}$ & Management of Hypertension & 38 \\
\hline Ciprofloxacin & Quinolone Antibiotic & Treatment of otitis media & 39 \\
\hline Timolol maleate & Nonselective $\beta$-adrenergic blocker & Management of Hypertension & 40 \\
\hline Ketoconazole & Azole antifungal & Antimicrobial activity & 41 \\
\hline
\end{tabular}




\begin{tabular}{|l|l|l|l|}
\hline $\begin{array}{l}\text { Diclofenac diethylamine, } \\
\text { Curcumin }\end{array}$ & $\begin{array}{l}\text { NSAID and natural Phenol } \\
\text { curcuminoid }\end{array}$ & Analgesic and Anti-inflammatory & 42 \\
\hline Itraconazole & Antifungal triazoles & Formulation Optimization & 43 \\
\hline Paromomycin sulfate & Antibiotic & cutaneous leishmaniasis & 44 \\
\hline risperidone & antipsychotics & Formulation Optimization & 45 \\
\hline Minoxidil and caffeine & Antihypertensive vasodilator & Treatment of alopecia & 46 \\
\hline $\begin{array}{l}\text { Raloxifene } \\
\text { Hydrochloride }\end{array}$ & $\begin{array}{l}\text { Selective eoestrogen receptor } \\
\text { modulator (SERM) }\end{array}$ & Treatment of osteoporosis & 47 \\
\hline $\begin{array}{l}\text { sinomenine } \\
\text { hydrochloride }\end{array}$ & Alkaloid & $\begin{array}{l}\text { Formulation optimization Treatment of } \\
\text { Rheumatism }\end{array}$ & 48 \\
\hline Embelin & Benzoquinone derivative & Treatment of Cancer & 49 \\
\hline Indinavir sulfate & $\begin{array}{l}\text { Protease inhibitor used as a } \\
\text { component of highly active } \\
\text { antiretroviral therapy to treat } \\
\text { HIV/AIDS }\end{array}$ & $\begin{array}{l}\text { Treatment against AIDS with other } \\
\text { protease inhibitors, nucleoside analogues } \\
\text { or reverse transcriptase inhibitors }\end{array}$ & 50 \\
\hline Stavudine & Reverse transcriptase inhibitors & Prevention and treatment of HIV/AIDS & 51 \\
\hline
\end{tabular}

\section{CONCLUSION}

Transfersomes has several advantages of transdermal drug delivery system. Transfersomes can entrap and deliver small and large molecules effectively through skin. Their ultradeformable property makes them to overcome the skin permeation difficulty, as they squeeze themselves to cross the skin layer barriers. But for

\section{REFERENCES}

1. Mandal SC, Mandal M, Current status and future prospects of new drug delivery system, Pharm Times, 2010; 42(4):13-6.

2. Bhatt S, Nimkar S, Clinical Research in Ayurveda: A Preliminary Review of 225 Papers Published In Indian Ayurveda Journals, Journal of Dental and Medical Sciences, 2015; 14 (2):43-50.

3. Bhokare SG, Dongaonkar CC, Lahane SV, Salunke PB, Sawale VS and Thombare MS, Herbal Novel Drug Deliver: A Review, World Journal of Pharmacy and Pharmaceutical Sciences, 2016; 5 (8):593-611.

4. Lakshmi PK, Kalpana B, Prasanthi D, Invasomes-Novel Vesicular Carriers for Enhanced Skin Permeation, Systematic Reviews in Pharmacy, 2013; 4 (1):26-30

5. Merdan VM, Alhaique F, and Touitou E, Vesicular carriers for topical delivery, Acta Techno. Legis Medicament, 1998, 12, 16.

6. Ranga S, Kumar A, Pharmacosome A Review on Pharmacosomes: Research and Reviews, Journal of Pharmaceutics and Nanotechnology, 2014; 2 (1):7-12.

7. Khurana B, Bajaj R, Girotra L, Vesosomal Drug Delivery In Liposomes: A Review, International Journal of Pharmacy, 2012; 2(4):768-776.

8. Chandrika MV, Manasa GS, Mounical PL, Varsha PH, Bhavyasri P, Sphingosomes: A Novel Approach for Vesicular Drug Delivery System, American Journal of PharmTech Research, 2016; 6 (2):119-130.

9. Arora $\mathrm{N}$, Agarwal S, Murthy RSR, Niosomes: Latest Technology Advances in Cosmaceuticals , International Journal of Pharmaceutical Sciences and Drug Research, 2012; 4(3):168182.

10. Pople PV, Singh KK, Nanoparticles: Development and evaluation of topical formulation containing solid lipid nanoparticles of vitamin A, American Association of Pharmaceutical Scientists PharmSci Tech, 2006; 7, 91.

11. Chaturvedi M, Kumar M, Sinhal A, Saifi A, Microemulsions: Recent development in novel drug delivery systems of herbal drugs, International Journal of Green Pharmacy, 2011; 5:87-94.

12. Ashish Y. Pawar, Jadhav KR, Chaudhari LH, Transfersome: A Novel Technique Which Improves Transdermal Permeability, Asian Journal of Pharmaceutics, 2016 (Suppl), 10; (4):S425S436. optimized formulation the most critical factor is correct ratio of edge activators and phospholipids, which governs the flexibility, vesicle layers integrity, and entrapment efficiency and stability of the formulation. Transfersomes has explored for delivery of macro and micro molecules, but lots of phytoconstituents are there to explore the potential role of this delivery system.
13. Romero EL, Morilla MJ, Highly deformable and highly fluid vesicles as potential drug delivery systems: Theoretical and Practical considerations, International journal of Nanomedicine, 2013; 8:3171-3186.

14. Jain S, Sapre R, Jain NK, Proultraflexible lipid vesicles for effective transdermal delivery of norgesterol, proceedings of 25th conference of C.R.S., U.S.A., 1998; 32-35.

15. Cevc G, Blume G, Lipid vesicles penetrates into intact skin owing to the transdermal osmotic gradients and hydration force, Biochim. Biophys Acta, 1992; 1104:226-232.

16. Jain NK. Advances in Controlled and Novel Drug Delivery. Ed. 1. New Delhi: CBS Publishers and Distributers; 2001. P. 426451.

17. Planas ME, Gonzalez P, Rodriguez L, Noninvasive percutaneous induction of topical analgesia by a new type of drug carrier, and prolongation of local pain insensitivity by anesthetic liposomes, Anesthesia \& Analgesia, 1992; 75:615621

18. Sinico C, Fadda AM, vesicular carriers for dermal drug delivery, Expert Opinion on drug delivery, 2009; 6:813-825.

19. Lane ME, Skin penetration enhancers, International Journal of Pharmaceutics, 2013; 447:12-21.

20. Bergh BAIVD, Wertz PW, Junginger HE, Bouwstra JA, Elasticity of vesicles assessed by electron spin resonance, electron microscopy and extrusion measurements, International Journal of Pharmaceutics, 2001; 217(1-2):13-24.

21. Yoshioka T, Sternberg BF, Lorence AT, Preparation and properties of vesicles (niosomes) of sorbitan monoesters (Span 20, 40, 60 and 80) and a sorbitan triester (Span 85), International Journal of Pharmaceutics, 1994; 105:1-6

22. Ghada M, Holayel SM, Mortada ND, Role of edge activators and surface charge in developing ultradeformable vesicles with enhanced skin delivery, International Journal of Pharmaceutics, 2010; 397:164-172.

23. Kulkarni PR, Yadav JD., Vaidya KA, Gandhi PP, Transfersomes: An emerging tool for transdermal drug delivery, International Journal of Pharmaceutical Sciences and Research, 2011; 2:735-741

24. Prajapati ST, Patel CG, Patel CN, Transfersomes: A vesicular carrier system for transdermal drug delivery, Asian Journal of Biochemical and Pharmaceutical Research, 2011;2:507-524. 
25. Sachan R, Parashar T, Soniya, Singh V, Tyagi S, Patel C, Gupta A, Drug Carrier Transfersomes: A Novel Tool for Transdermal Drug Delivery System, International Journal of Research and Development in Pharmacy and Life Sciences, 2013; 2(2):309316.

26. Shaw JE, Chandrasekaran SK. Pharmacology of the skin, Greaves. Berlin: Springer-Verlag; 1999. P. 115-122.

27. Walve JR, Bakliwal SR, Rane BR, Pawar SP, Transfersomes: A Surrogated Carrier for Transdermal Drug Delivery System, International Journal of Applied Biology and Pharmaceutical Technology, 2011; 2 (1):204-213.

28. Vyas SP, Kahtri K, Mishra V, Vesicular carriers constructs for topical immunization, Expert Opinion Drug Delivery, 2007; 4:341-348

29. Paul A, Cevc G, Bacchawat BK, Transdermal immunization with and integral membrane component, gap junctional protein by means of ultradeformable drug carriers: Transfersomes, Vaccine, 1998; 16:188-195.

30. Mahore S, Rawat A, Dubey PK, Goyal AK, Cationic transfersomes based topical genetic vaccine against Hepatitis B, International Journal of Pharmaceutics, 2007; 340(1-2):13-19.

31. Cevc G, Blume G, schatzlein A, Gebauer D, and Paul A, The skin: a pathway for systemic treatment with patches and lipidbased agent carriers, Advance drug delivery reviews, 1996; 18(3):349-378.

32. Hofer C, Gobel R, Deering P, Lehmer A, Breul J, Formulation of Interleukine- 2 and Interferon $-\alpha$ containing ultradeformable carriers for potential transdermal application, Anticancer Research, 1999; 19:1505-1507.

33. Cevc G, Gebauer D, Stieber J, Schatzlein A, Blume G, Ultraflexible vesicles, Transfersomes, have an extremely low pore penetration resistance and transport therapeutic amounts of insulin across the intact mammalian skin, Biochimica et Biophysica Acta, 1998; 1368:201-215.

34. Jain S, Jain P, Uma Maheshwari RB, Jain NK, Transfersomes-A Novel Vesicular Carrier for Enhanced Transdermal Delivery: Development, Characterization, and Performance Evaluation, Drug Development and Industrial Pharmacy, 2003; 29(9):1013-1026.

35. Cevc G, Blume G, New highly efficient formulation of diclofenac for the topical, transdermal administration in ultradeformable drug carriers: Transfersomes, Biochimica et Biophysica Acta, 2001; 1514:191-205.

36. Lei W, Yu C, Lin H, Zhou X, Development of tacrolimusloaded transfersomes for deeper skin penetration enhancement and therapeutic effect improvement in vivo, Asian Journal of Pharmaceutical Sciences, 2013; 8 (6):336-345.

37. Ahmed H, Shuwaili AL, Bazigha K, Rasool A, Alaa, Rasool A, Optimization of elastic transfersomes formulations for transdermal delivery of pentoxifylline, European Journal of Pharmaceutics and Biopharmaceutics, 2016; 102:101-114.

38. Ahad A, Al-Saleh AA, Al-Mohizea AM, Al-Jenoobi FI, Raish M, Eldeen AB, Yassin, Alam MA, Pharmacodynamic study of eprosartan mesylate-loaded transfersomes Carbopol® gel under Dermaroller ${ }^{\circledR}$ on rats with methyl prednisolone acetate-induced hypertension, Biomedicine \& Pharmacotherapy, 2017; 89:177184

39. Al-Mahallawi AM, Khowessah O, Shoukri RA, Nanotransfersomal ciprofloxacin loaded vesicles for non-invasive trans-tympanic ototopical delivery: In-vitro optimization, exvivo permeation studies, and in-vivo assessment, International Journal of Pharmaceutics, 2014; 472(1-2):304-314.

40. Nadia M, Ahmed AM, MarwaAW, Dawoud HS, Improved bioavailability of timolol maleate via transdermal transfersomal gel: Statistical optimization, characterization, and pharmacokinetic assessment, Journal of Advanced Research, 2016; 7 (5):691-70.

41. Singh S, Verma D, Aamir M, et al. Development and optimization of ketoconazole loaded nano-transfersomal gel for vaginal delivery using Box-Behnken design:In vitro, ex vivo characterization and antimicrobial evaluation, Journal of Drug Delivery Science and Technology, 2017; 39:95-10.

42. Chaudhary H, Kohli K, Kumar V, Nano-transfersomes as a novel carrier for transdermal delivery, International Journal of Pharmaceutics, 2013; 454(1):367-380.

43. Zheng WS, Fang XQ, Wang LL, Zhang YJ, Preparation and quality assessment of itraconazole transfersomes, International Journal of Pharmaceutics, 2012; 436(1-2):291-298.

44. Bavarsad N, Bazzaz BSF, Khamesipour A, Jaafari MR, Colloidal, in vitro and in vivo anti-leishmanial properties of transfersomes containing paromomycin sulfate in susceptible BALB/c mice, Acta Tropica, 2012; 124(1):33-41.

45. Das B, Sen SO, Maji R, Nayak AK, Sen KK, Transferosomal gel for transdermal delivery of risperidone: Formulation optimization and ex vivo permeation, Journal of Drug Delivery Science and Technology, 2017; 38:59-71.

46. Ramezani V, Honarvar M, Seyedabadi M, Karimollah A, Hashemi M, Formulation and optimization of transfersomes containing minoxidil and caffeine, Journal of Drug Delivery Science and Technology, 2018; 44:129-135.

47. Joshi A, Kaur J, Kulkarni R, Chaudhari R, In-vitro and Exvivo evaluation of Raloxifene hydrochloride delivery using nano-transfersomes based formulations, Journal of Drug Delivery Science and Technology, 2018; 45:151-158.

48. Wang J, Wei Y, Fei YR, Fang L, Zheng HS, Chao-FengMu, Fan-ZhuLi, Zhang YS, Preparation of mixed monoterpenes edge activated PEGylated transfersomes to improve the in vivo transdermal delivery efficiency of sinomenine hydrochloride, International Journal of Pharmaceutics, 2017; 533(1):266-274.

49. Jain S, Jain N, Formulation and Evaluation of Embelin Loaded Transfersome for Effective Treatment of Skin Cancer, Journal of Thoracic Oncology, 2017; 12(1152):S2378.

50. Enhanced Transdermal delivery of indinavir sulfate via transfersomes, DM Sheo, A Shweta, KT Vijay, CD Ram, S Aklavya - Pharmacie Globale (IJCP), 2010; 1(06):1-7

51. Formulation Development and Evaluation of Ethosome of Stavudine Maurya SD, Prajapati SK, Gupta AK, Saxena GK, Dhakar RC, Indian J. Pharm. Educ. Res. 2010 Jan-Mar; 44(1):102-108. 